\title{
Compatibility Problem
}

National Cancer Institute

\section{Source}

National Cancer Institute. Compatibility Problem. NCI Thesaurus. Code C62983.

Problem associated with compatibility between device, patients or substances

(medication, body fluid, etc.). 